Revista Tecné, Episteme y Didaxis: TED. Año 2014, Número Extraordinario. ISSN Impreso: 0121-3814, ISSN web: 2323-0126 Memorias, Sexto Congreso Internacional sobre Formación de Profesores de Ciencias. 08 al 10 de octubre de 2014, Bogotá

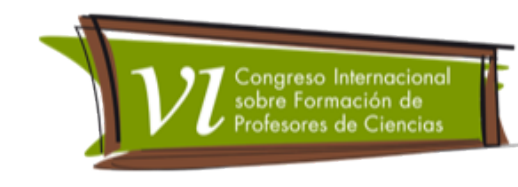

\title{
A prática pedagógica de Ciências: um exemplo de problematização de tecnologias no Ensino Fundamental
}

Miquelin Awdry Feisser', Darronqui Silvia Regina².

Categoría 2. Trabajo de investigación (en proceso)

\section{Resumo}

Este artigo trata de alguns resultados de pesquisa de mestrado, cujo problema foi: Problematizar as tecnologias pode propiciar a construção de conhecimento diferenciado no ensino-aprendizagem de Ciências? São objetivos desafiar a aprendizagem com questões científicas e tecnológicas não tratadas tradicionalmente e problematizar o ensino de Física para o Ensino Fundamental. Fundamentou-se em Freire, Vicente, Pacey, Postman e Bazzo, entre outros. A coleta de dados se deu por questionário inicial e final, diário de campo e transcrições de áudio. Os dados foram analisados considerando eixos inspirados pelo "Ato de ler" de Freire. Verificou-se que os estudantes deixaram a visão ingênua das tecnologias, analisaram-nas em seu contexto e se apropriaram de conteúdos que Ihes fizeram sentido; promoveu-se o diálogoproblematizador sobre tecnologias na disciplina de ciências.

\section{Palavras-chave}

Ciências. CTS. Problematização. Tecnologia.

\section{Marco teórico}

Por que discutir questões CTS com os estudantes?

\footnotetext{
1 Universidade Tecnológica Federal do Paraná - UTFPR, Departamento Acadêmico de Física DAFIS, Programa de Pós-Graduação em Formação Educacional Científica e Tecnológica FCET, Programa de Pós Graduação em Educação em Ciências e em Matemática - PPGECM. awdry@utfpr.edu.br

2 Secretaria de Estado da Educação do Paraná - SEED/PR. silviareginadarronqui@yahoo.com
} 
Revista Tecné, Episteme y Didaxis: TED. Año 2014, Número Extraordinario. ISSN Impreso: 0121-3814, ISSN web: 2323-0126 Memorias, Sexto Congreso Internacional sobre Formación de Profesores de Ciencias. 08 al 10 de octubre de 2014, Bogotá

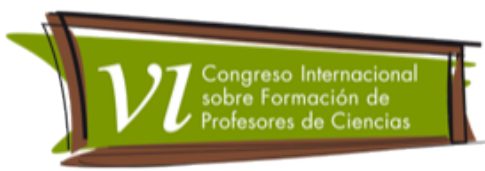

Não há dúvida de que as tecnologias são vantajosas pois "tornam a vida mais fácil, mais limpa e mais longa" (Postman, 1994, pág. 12). Elas nos poupam trabalho, permitem contatar pessoas, nos informam e servem como entretenimento. Esse benfazer da tecnologia é chamado por Álvaro V. Pinto (2005) de "maravilhamento do homem diante das suas criações." Segundo ele não se vê o que está subentendido no agir da tecnologia, pois existem aspectos em que podem ser um fardo à cultura, ao trabalho, às relações humanas e de trabalho e ao meio ambiente. Já Postman (1994) trata da influência da tecnologia na cultura dos povos e afirma que as pessoas "vêem apenas o que as novas tecnologias podem fazer e são incapazes de imaginar o que elas irão desfazer". (Postman, 1994, pág.15). Vicente (2005) utiliza o termo tecnologia enlouquecida para definir o quanto os seres humanos modificam hábitos e se adaptam às tecnologias.

As pessoas geralmente não se colocam no mundo tecnológico para refletir sobre ele, não sabem que "toda tecnologia, [...], transporta inevitavelmente um conteúdo ideológico" (Pinto, 2005, pág. 320).

Assim, quando inseridas na sociedade têm um valor ideológico que determina seu papel e normalmente relaciona-se à dominação das massas populares. As pessoas não têm ideia desse papel e adquirem toda nova tecnologia; não sabem que toda tecnologia não é somente um artefato utilitário e funcional, mas está carregada de símbolos culturais que caracterizam o ser humano e a sociedade. (Pereira, Bazzo, 2010).

A escola pode colaborar para que os estudantes vejam a necessidade da análise crítica sobre as tecnologias nos dias atuais, pois:

É preciso que as pessoas sejam conscientizadas do amplo universo que a Ciencia e a Tecnologia incorporam e como os seus valores demonstram dramaticamente $\mathrm{seu}$ grau de importância no avanço do conhecimento, do bem-estar e também dos riscos e prejuízos. (Bazzo, 2010, pág. 31)

Bazzo (2010) ainda afirma que o cidadão deve aprender a ler e a entender todas as implicações da Ciência e da Tecnologia, pois este conhecimento pode potencializar suas decisões de ordem política e social. Acredita-se que a escola pode aguçar esta visão crítica. 
Revista Tecné, Episteme y Didaxis: TED. Año 2014, Número Extraordinario. ISSN Impreso: 0121-3814, ISSN web: 2323-0126 Memorias, Sexto Congreso Internacional sobre Formación de Profesores de Ciencias. 08 al 10 de octubre de 2014, Bogotá

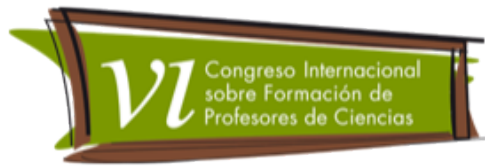

Aproximações entre $O$ ato de ler de Freire e as tecnologias.

Visando propiciar aos estudantes uma leitura diferenciada sobre as tecnologias presentes em seu contexto, buscou-se em Freire (1989) o entendimento de uma forma de leitura racional e transformadora. Em seu livro "A importância do ato de ler: em três artigos que se completam" trata do que é relevante na leitura para o entendimento das palavras e do mundo. Vistos como significativos na leitura das tecnologias estes pontos fundamentaram essa pesquisa e geraram eixos entre o "ato de ler de Freire e as tecnologias" (Darronqui, 2013, pág. 47). Neste trabalho apenas comentamos os eixos analisados na sequência didática que será comentada em seguida.

Freire (1989) trata da importância da leitura crítica, reflexiva e não mecânica do texto e do mundo. Esta reflexão é transposta para as tecnologias, visando a análise crítica de suas implicações na sociedade. A leitura crítica é essencial para conhecer a tecnologia utilizada.

Freire (1989) tratou sobre a magicização da palavra e se propõe esse conceito para as tecnologias, visto que os estudantes as magicizam e não percebem que estas também causam danos. Pacey (1990) chama essa magicização de "misticismo pela máquina". Tratando deste tema Postman (1994) afirma que:

No tecnopólio, estamos cercados pelos efeitos maravilhosos das máquinas e somos encorajados a ignorar as ideias neles embutidas. 0 que significa que ficamos cegos para o significado ideológico de nossas tecnologias. (Postman, 1994, pág.101).

"Ninguém ignora tudo. Ninguém sabe tudo. Todos nós sabemos alguma coisa. Todos nós ignoramos alguma coisa." (Freire, 1989, pág. 39); nas tecnologias é impossível saber tudo, pois sem nos atermos, ela caminha conosco e "temos que nos adaptar à tecnologia digital que se move à velocidade da luz." (Vicente, 2005, pág. 24).

\section{Metodologia}

Fez-se uma aproximação teórica das discussões CTS em torno dos referenciais citados com o ato de ler de Freire na prática em sala de aula pela problematização dos conteúdos previstos no currículo, que se deu da seguinte forma: vinculadas as reflexões 
Revista Tecné, Episteme y Didaxis: TED. Año 2014, Número Extraordinario. ISSN Impreso: 0121-3814, ISSN web: 2323-0126 Memorias, Sexto Congreso Internacional sobre Formación de Profesores de Ciencias. 08 al 10 de octubre de 2014, Bogotá

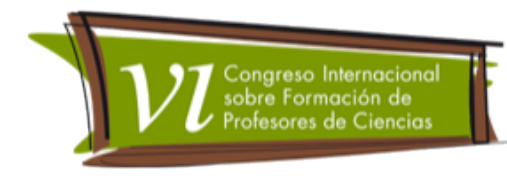

teóricas aos conteúdos da disciplina de Ciências, foram criadas sequências didáticas que propunham problematizações referentes a produtos tecnológicos com o tema gerador Satélites Artificiais. Cada sequência foi estruturada nos três momentos pedagógicos (Delizoicov, 2008).

Na observação do desenvolvimento das aulas e das falas dos estudantes, seguiu-se a espiral de ciclos da pesquisa-ação (Kemmis \& Mctaggart, 1988) a cada sequência desenvolvida com a turma; existindo a necessidade frente às análises realizadas, a sequência era reestruturada, partindo assim para um novo ciclo de inserção e análise na turma seguinte, na qual as sequências didáticas sofreram várias modificações durante a ação. Cremos que essas modificações também são um avanço, pois com elas as sequências foram aprimoradas.

O tema gerador tem potencialidades que provocaram e estimularam seu estudo relacionando-o ao contexto do aluno. Abaixo se mostram alguns dos questionamentos realizados (Ver tabela 1 ).

Tabela 1. Perguntas que suscitaram o estudo.

\begin{tabular}{|c|c|}
\hline $\begin{array}{l}\text { TEMA } \\
\text { GERADOR }\end{array}$ & PERGUNTAS QUE SUSCITARAM O ESTUDO \\
\hline \multirow{6}{*}{$\begin{array}{l}\text { Satélites } \\
\text { artificiais }\end{array}$} & $\begin{array}{l}\text { A televisão da sua casa funciona com o sinal analógico ou com o sinal digital? } \\
\text { Comente o que é o sinal analógico e o sinal digital. }\end{array}$ \\
\hline & Escreva a relação existente entre o seu celular e os satélites. \\
\hline & $\begin{array}{l}\text { Como a voz de uma pessoa tão distante pode chegar até o seu celular? } \\
\text { Relacione o uso do seu celular com os satélites. }\end{array}$ \\
\hline & $\begin{array}{l}\text { Para que serve um GPS? Faça uma relação entre o funcionamento do GPS com } \\
\text { os satélites. }\end{array}$ \\
\hline & $\begin{array}{l}\text { Como um satélite é colocado em órbita? Eles andam ou ficam parados no mesmo } \\
\text { lugar? }\end{array}$ \\
\hline & Descreva um satélite. O que mudaria no mundo atual sem os satélites? \\
\hline
\end{tabular}

As sequências foram aplicadas a estudantes de quatro turmas de $9^{\circ}$ ano do Ensino Fundamental, na disciplina de Ciências, num Colégio da rede Estadual do Paraná durante o segundo semestre de 2012.

Cita-se neste artigo a $2^{a}$ sequência didática que trata dos conteúdos previstos no currículo: Movimento, Trajetória e Energia. Os momentos pedagógicos ocorreram da seguinte forma (Ver tabela 2):

Temática 1. Enfoque CTS: Alfabetización científica y Cuestiones socio científicas 
Revista Tecné, Episteme y Didaxis: TED. Año 2014, Número Extraordinario. ISSN Impreso: 0121-3814, ISSN web: 2323-0126 Memorias, Sexto Congreso Internacional sobre Formación de Profesores de Ciencias. 08 al 10 de octubre de 2014, Bogotá

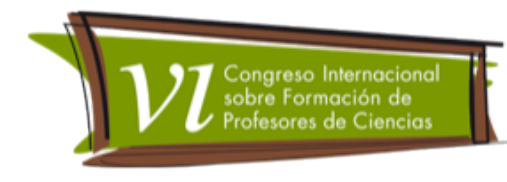

Tabela 2. Momentos pedagógicos da $2^{a}$ sequência didática.

\begin{tabular}{|c|c|}
\hline $\begin{array}{l}\text { Problematização do } \\
\text { conhecimento }\end{array}$ & $\begin{array}{l}\text { Questionamento feito aos alunos antes da realização de qualquer } \\
\text { trabalho neste conteúdo: Descreva um satélite artificial. O que mudaria } \\
\text { no mundo atual sem os satélites artificiais? }\end{array}$ \\
\hline $\begin{array}{l}\text { Organização do } \\
\text { conhecimento }\end{array}$ & $\begin{array}{l}\text { Utilizando imagens e vídeos explicou-se sobre satélites artificiais, com a } \\
\text { professora questionando e sendo a ponte entre o conhecimento } \\
\text { apresentado e o contexto dos alunos. }\end{array}$ \\
\hline $\begin{array}{l}\text { Aplicação do } \\
\text { conhecimento }\end{array}$ & $\begin{array}{l}\text { Os alunos responderam oralmente e de forma escrita à questão } \\
\text { inicialmente levantada, utilizando-se dos conhecimentos adquiridos. }\end{array}$ \\
\hline Eixos observados & $\begin{array}{l}\text { - } \quad \text { Magicização da tecnologia. } \\
\text { - } \quad \text { Nas tecnologias "ninguém ignora tudo. Ninguém sabe tudo. Todos nós } \\
\text { sabemos alguma coisa. Todos nós ignoramos alguma coisa". } \\
\text { - } \quad \text { Leitura crítica das tecnologias. }\end{array}$ \\
\hline
\end{tabular}

A coleta de dados se deu por registros em diário de campo, respostas a questionário aplicado aos alunos e transcrição das aulas do segundo semestre de 2012 gravadas em áudio. A análise dos dados coletados considerou os eixos criados na relação "ato de ler" de Freire e as tecnologias.

\section{Resultados}

Apresenta-se alguns resultados das discussões geradas nesta sequência didática pelo recorte abaixo de uma transcrição de áudio gravada na turma $9^{\circ} \mathrm{C}$ no dia 29/10/12 (Ver tabela 3):

Tabela 3. Transcrição de áudio.

PROFESSORA: mas quem ia pagar essa placa solar na casa da gente?

ALUNA: nos impostos, um imposto a mais não ia fazer diferença. [...]

ALUNO: assim, a gente ia pagar a placa à prestação. [...]

ALUNO: não é tão cara uma placa. [...]

ALUNA: e daí a energia elétrica só seria usada quando acabasse a solar, assim, temporariamente.

PROFESSORA: e por que você acha que não acontece isso? 
Revista Tecné, Episteme y Didaxis: TED. Año 2014, Número Extraordinario. ISSN Impreso: 0121-3814, ISSN web: 2323-0126 Memorias, Sexto Congreso Internacional sobre Formación de Profesores de Ciencias. 08 al 10 de octubre de 2014, Bogotá

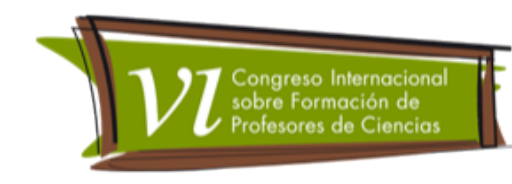

ALUNA: porque eles querem ganhar o dinheiro da energia elétrica.

ALUNA: e também quantas pessoas não perderiam o emprego se acontecesse isso, [...], os que trabalham na luz elétrica, trabalham pra manter os cabos da rua, os que trabalham no atendimento.

ALUNO: mas teriam os que iam manter as placas.

ALUNA: mas seria menos gente, bem menos gente.

O trecho mostra as discussões nas quais os estudantes romperam com a passividade; a aula proporcionou uma reflexão que envolveu o tema da aula e outras questões que extrapolaram o tema.

Considerando os eixos da relação "ato de ler" de Freire (1989) e as tecnologias podese verificar que houve magicização da tecnologia ao se imaginar a plena facilidade de implantar a placa solar em relação aos custos - "não é tão cara uma placa", por falta de conhecimento sobre o assunto, ao ignorar a dificuldade de implantação e sem considerar os problemas de manutenção. O que permite também tratar do segundo eixo desta sequência, na qual os estudantes conhecem superficialmente sobre a produção de energia elétrica, mas ignoram completamente os outros fatores relacionados à implantação e manutenção de placas solares.

A leitura crítica da tecnologia - placa solar - se mostrou presente em toda a discussão em relação às questões políticas a ela envolvidas: "quantas pessoas que não perderiam o emprego", "Não tem placas feitas de materiais recicláveis?", "eles querem ganhar o dinheiro da energia elétrica"; nas quais os estudantes discutiram alguns pontos envolvidos na implantação ou não das placas solares. Foi uma discussão inicial, mas coerente para a transposição didática pautada na faixa etária dos estudantes. Considerou-se assim, que numa abordagem livresca e mecanicista estas discussões não ocorreriam.

\section{Conclusões}

A sociedade adota todos os artefatos tecnológicos inventados, mas não os conhece. Por este motivo o estudo crítico das tecnologias é necessário e pode se iniciar no Ensino Fundamental para contribuir com a formação de sujeitos que saibam refletir 
Revista Tecné, Episteme y Didaxis: TED. Año 2014, Número Extraordinario. ISSN Impreso: 0121-3814, ISSN web: 2323-0126 Memorias, Sexto Congreso Internacional sobre Formación de Profesores de Ciencias. 08 al 10 de octubre de 2014, Bogotá

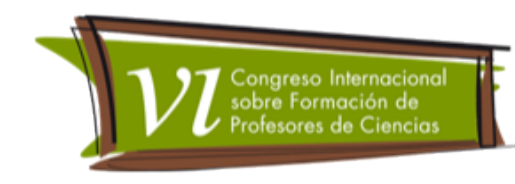

sobre o processo artefato-sociedade. Esta pesquisa procurou relacionar estes dois aspectos visando à leitura crítica das tecnologias.

As práticas relacionadas à leitura de alguns produtos tecnológicos levaram os estudantes à análise das tecnologias e as relacionar ao seu contexto, objetivando que abandonassem o maravilhamento pela máquina citado por Pinto (2005) para serem os leitores segundo Freire (1989).

Confirmou-se a necessidade de analisar as tecnologias de acordo com Bazzo (201), Postman (1994) e Vicente (2005) pela ingenuidade inicial dos estudantes, na qual confirmamos também a necessidade da realização da intervenção proposta.

Pode-se afirmar que na realidade investigada a problematização das tecnologias proporcionou a construção de conhecimento diferenciado no processo ensinoaprendizagem de Ciências. Assim, a educação tecnológica propiciou o conhecimento científico relacionado à compreensão das tecnologias e guiou os alunos a questionarem, em sala de aula, fatos cotidianos relacionados aos produtos tecnológicos que têm contato, envolvendo inclusive questões políticas. Isto foi possível pela abordagem problematizadora das tecnologias.

A construção de conhecimentos no processo ensino-aprendizagem de Ciências se deu nas atividades realizadas em sala de aula, pelos questionamentos e pelas respostas dos alunos ao problema inicialmente levantado, dados estes colhidos nas transcrições, no diário de campo e no questionário final. A problematização inicial levantava questões referentes às tecnologias relacionadas ao cotidiano das pessoas e, após o trabalho realizado, os estudantes responderam às questões utilizando conhecimentos científicos trabalhados dentro do conteúdo previsto na disciplina de Ciências. Assim, aprender Ciências mostrou-se fundamento efetivo para a compreensão das relações tecnológicas presentes no dia a dia.

\section{Referências bibliográficas}

Bazzo, W. A. (2010). Ciência, tecnologia e sociedade: e o contexto da educação tecnológica. ( $2^{a}$ ed.rev.e atual). Florianópolis, Santa Catarina: Ed. da UFSC. 
Revista Tecné, Episteme y Didaxis: TED. Año 2014, Número Extraordinario. ISSN Impreso: 0121-3814, ISSN web: 2323-0126 Memorias, Sexto Congreso Internacional sobre Formación de Profesores de Ciencias. 08 al 10 de octubre de 2014, Bogotá

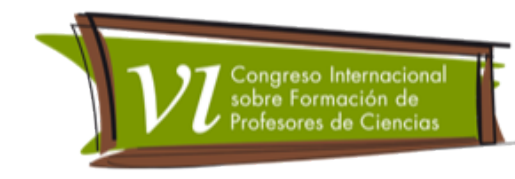

Darronqui, S. R. Do uso à mediação de tecnologias no ensino-aprendizagem de ciências: uma abordagem investigativa de prática educacional no ensino fundamental. 2013. Dissertação - Universidade Tecnológica Federal do Paraná, Curitiba, 2013. Consultado em: http://repositorio.utfpr.edu.br/jspui/handle/1/617.

Delizoicov, D. La Educación en Ciencias y la Perspectiva de Paulo Freire. ALEXANDRIA Revista de Educação em Ciência e Tecnologia, v.1, n.2, p.37-62, jul. 2008. ISSN 1982-5153. Consultado em:

http://alexandria.ppgect.ufsc.br/files/2012/03/demetrio.pdf.

Freire, P. (1989). A importância do ato de ler: em três artigos que se completam. (23a Ed.). São Paulo: Cortez.

Kemmis, S., MCTAGGART, R. (1988). Como Planificar La Investigación-Accion. (3a ed.). Barcelona: Alertes.

Miquelin, A. F. (2009). Contribuições dos meios tecnológicos comunicativos para o ensino de Física na escola básica. Tese (Doutorado em Educação) - Universidade Federal de Santa Catarina. Florianópolis, SC.

Pacey, A. (1990). La cultura de la tecnologia. Cidade do México: Fondo de Cultura Econômica.

Pereira, L. T. do V., BAZZO, W. A. (2010). A tecnologia e o Homo Simbolicus. COBENGE Congresso Brasileiro de Educação em Engenharia, XXXVIII. Fortaleza-CE. Consultado em: http://www.abenge.org.br/cobenges-anteriores/2010/artigos2010/artigos-publicados_12.

Pinto, A. V. (2005). O Conceito de Tecnologia. (Volume 1). Rio de Janeiro: Contraponto.

Postman, N. (1994). Tecnopólio: a rendição da cultura à tecnologia. Tradução Reinaldo Guarany. São Paulo: Nobel.

Vicente, K. J. (2005). Homens e máquinas. Tradução Maria Inês Duque Estrada. Rio de Janeiro: Ediouro. 